\title{
El tabernáculo de la catedral de Lugo, un ejemplo de neobarroco romano
}

\author{
Adolfo de Abel Vilela
}

Desde el punto de vista del historiador del arte, el estudio de lo que se viene llamando "Neoclasicismo", plantea una serie de dudas y problemas a los que aún no se ha dado una respuesta definitiva, quizá por una falta de análisis en profundidad de este fenómeno artístico, en cuanto a la arquitectura se refiere, o por temor a romper con teorias asentadas, más por inercia y rutina, que por un estudio detenido y objetivo del problema. Algunos trabajos sobre el tema, de los que esperábamos aportaciones novedosas en este campo, si bien en algún momento parece que intuyeron la cuestión, debió de pasarles desapercibida o no se atrevieron a plantearla.

Quizá uno de los graves errores en los que con frecuencia caemos los historiadores en general, es querer sistematizarlo todo, haciendo traslación de fenómenos artísticos foráneos a nuestro entorno, en un afán comparativo que no resiste un análisis medianamente objetivo. Creo que ha llegado el momento de hacer una revisión en profundidad de lo que llamamos "neoclasicismo" en España, o al menos, a la arquitectura religiosa que se hace en el reinado de Carlos III (1759-1788).

La sensibilidad artística de este rey, educado en un ambiente familiar de aficionados a las colecciones de arte, estará presente a lo largo de su vida tanto en las Dos Sicilias como en España, pero, además, contribuirá a fomentar una cultura arqueologista e historicista, que van a sentar las bases teóricas e ideológicas de lo que posteriormente, y a falta de mejor nombre, llamamos “romanticismo". Por tanto, creemos que su política artística no fue la de oponerse al barroco, sino la de depurarlo, devolverlo a la pureza del primer barroco italiano como evolución de la arquitectura del "Renacimiento». Sólo en este sentido creo que se puede hablar de "clasicismo", pero nunca de "neoclasicismo", por que este es un revival, un historicismo. Estamos, pues, ante un eclecticismo y por ello habria que encasillarla dentro de la arquitectura del romanticismo. Patetta considera 
como arquitectura del eclecticismo, «el entramado y sucesión de experiencias revivalistas, con las que la burguesia ha tratado de determinar sus ideales figurativos" ".

La fecha de 1750 la considera, convencionalmente, como el umbral de la arquitectura de los revivals, pero tiene un significado preciso dado que en los años siguientes se va a manifestar de manera concreta la crisis del vitrubianismo o tradición de la arquitectura clásica, minado por las teorias racionalistas de Cordemoy y Laugler, los descubrimientos arqueológicos, el conocimiento de civilizaciones remotas y la difusión de nuevas teorias estéticas basadas en el principio de lo sublime y en la poética de lo pintoresco.

Asi, en España tenemos que hablar de un «neobarroco romano", un revival que será el "estilo de la ilustración» española, frente al barroco que representa a las monarquias absolutas. Ahora bien, nuestra ilustración nada tiene que ver con la francesa. Es eminentemente tradicionalista y conservadora, que preconiza cambios y reformas, pero que rara vez ejecuta quedándose a medio camino. En definitiva, defiende sus intereses. Esta es, a nuestro entender, una de las razones por la que no llega al clasicismo puro, se queda en el primer barroco.

Pero tampoco debemos de olvidar que los "neos" son "revivals" con los que se identifica la naciente burguesía. Es necesario, pues, hablar de historicismo y, por consiguiente, de “eclecticismo» y "romanticismo». La capilla mayor de la catedral de Lugo, en donde se va a instalar el tabernáculo, se comienza a reconstruir en «neogótico» a principios del siglo xVIII, y después se ejecutará ese altar mayor en «neobarroco».

Sin embargo es preciso decir que en algunos trabajos recientes se ha intentado plantear la cuestión, abriendo la posibilidad de buscar nuevas vias interpretativas y de discusión sobre un estilo que en Galicia se desarrolla en el último tercio del siglo XVIII y primero del XIX, introducido por los ingenieros-arquitectos Militares que trabajan en las Reales Obras de O Ferrol, encargándose de propagar las ideas ilustradas, a la española, de los gobiernos de Carlos 111 y de la Real Academia de Bellas Artes de San Fernando, no sólo al ámbito de la arquitectura sino también a la del

Patetta, Luciano, Los revivals en arquitectura. (El pasado en el presente. El revival en las artes plásticas, la arquitectura, el cine y el teatro). Giulio Carlo Argan et. alt., pág. 129. Barcelona 1977. 
urbanismo" ${ }^{2}$. Por todo ello nuestra pretensión es aportar algunas ideas siguiendo esta línea de investigación, tomando como ejemplo el tabernáculo de la catedral de Lugo, obra que ha sido tratada con confusa paternidad, tal vez por falta de una más amplia utilización de las fuentes documentales, cuyos errores han llevado a la formulación de interpretaciones que, si bien son formalmente válidas, las consideramos científicamente incorrectas.

\section{LA RACIONALIDAD DE LOS INGENIEROS FRENTE AL CONCEPTO ARTISTICO DEL ARQUITECTO}

El papel renovador de los ingenieros en la creación de nuevas formas arquitectónicas, es algo que va a estar presente a lo largo del siglo XIX, restando protagonismo al arquitecto tradicional o artista, dando lugar a un cambio, no sólo en cuanto a técnica, sino también en lo que a la estética se refiere, creando un nuevo lenguaje y una nueva poética.

En el "clasicismo" que se hace en la catedral de Lugo, habria que diferenciar dos clarisimas influencias: la francesa y la italiana, a la que en lo sucesivo vamos a denominar como «romana». La primera estará presente en la remodelación del espacio interior de la capilla mayor, obra del ingeniero Carlos Lemaur. La segunda en la fachada principal, diseñada por Julián Sánchez Bort y en el tabernáculo de Pedro Ignacio de Lizaldi. Pero sin olvidar que en la influencia francesa está presente también la figura de Lorenzo Bernini.

Si hacemos una lectura detenida, tanto de la obra de la fachada como la del tabernáculo, diseñadas por ingenieros-arquitectos Militares, nos vamos a encontrar con que no son más que una transposición de un repertorio clásico, nacido del Renacimiento y codificado en el siglo xVII por arquitectos romanos, como Carlos Maderno y Lorenzo Bernini, que per-

\footnotetext{
${ }^{2}$ Sobre este punto se recomienda la lectura de los siguientes trabajos:

Izouierdo Perrin, Ramón, "La fachada priricipal de la catedral de Lugo", Abrente, núms. 16-17-18, págs. 7 a 40. La Coruña 1984.

VILA JATO, María Dolores, "Notas sobre la construcción de la fachada principal de la catedral de Lugo", Boletín del Seminario de Estudios de Arte y Arqueologia, t. LIV, pág. 465. Valladolid 1988.

Rosende VAldés, Andrés A., "Los retablos mayores de la catedral de Tui», Tui Museo y Archivo Histórico Diocesano, vol. V. págs. 67-99. Tui, 1989.

Vigo Trasancos, Alfredo, "La intervención del Estado dieciochesco en la arquitectura gallega de iniciativa privada: el papel de los ingenieros y la obra de Carlos Lemaur", La ingenieria militar en la cultura artistica española. Jornadas nacionales, noviembre. Cádiz 1989.
} 
durará hasta el siglo XVIII, en ejemplos como la fachada de San Giovanni Laterano (1735), de Alessandro Galilei, en donde tiene su paralelismo la fachada lucense.

El proyecto que para ella habia realizado Carlos Lemaur, fue rechazado por la Real Academia, probablemente por que su director Ventura Rodríguez apreciaba el lenguaje italianizante de su aprendizaje con Filippo Juvara y Giovan Battista Sacchetti, prefiriendo la racionalidad del barroco italiano, despojado del ornamento rococó, que contenia aquella depuración preconizada por Jacques-François Blondel, cuya influencia a través de su obra Architecture Française (1752-1756), es manifiesta en la renovación conceptual del nuevo estilo.

Se ejecutará en parte el de Sánchez Bort (1769), bajo la dirección de José de Elexialde, recogiendo soluciones y elementos que están presentes en el protobarroco romano de Maderno, en el barroco pleno de Bernini, y en el ultrabarroco de Galilei, prueba evidente del clasicismo existente en el barroco romano como una continuación de las formas del «Renacimiento", que aquí van a ser tomadas como modernas. Quizá, cuando en el siglo xix el Cabildo se plantea la terminación de la fachada con la construcción de las torres y habla de una obra "a la romana", seguramente no se está refiriendo al estilo greco-romano, sino a una obra "con base en la más pura tradición monumental romana" ${ }^{3}$. En los dos edificios que hemos mencionado como modelo, hay semejanzas que se observan «en el empleo en las dos fachadas del viejo motivo del orden palladiano que en los dos edificios es producto de la mentalidad clasicista y del deseo de asimilación de las fórmulas de los grandes arquitectos renacentistas que alentaban la arquitectura europea de los años centrales del siglo XVIII' ${ }^{4}$.

No debemos pasar por alto que a la condición de arquitecto de Bort hay que añadir la de ingeniero militar, y que estos tenian una visión diferente de la arquitectura, tal vez por su subordinación a las tácticas de guerra, y más concretamente al empleo del cañón, el uso del punto de mira, el tiro, y, consecuentemente, la línea recta y la parábola.

El ingeniero tiene una visión más racional de las formas, y más funcional de los espacios. Para ellos la decoración es supérflua e innecesaria desde el punto de vista de la utilidad. Las formas tienen que derivar

\footnotetext{
${ }^{3}$ VILA JATO, Maria Dolores "Notas sobre la construcción de la fachada principal de la catedral de Lugo", Boletin del Seminario de Estudios de Arte y Arqueologia, t. LIV, pág. 465. Valladolid 1988.

4 Ibidem.
} 
de una lógica de la construcción y no de una búsqueda de la belleza. Este funcionalismo de los ingenieros, chocaba con la idea que se tenia de los arquitectos como artistas, y con los intereses profesionales de estos últimos, que desde la Real Academia trataban de contrarrestar su influencia.

Es claro que después del recargamiento decorativo al que habia llegado el barroco en el siglo XVIII, que podemos ver en obras de arquitectos autóctonos como Fernando de Casas Novoa y Lucas Antonio Ferro Caaveiro, lo moderno tendría que ser lo foráneo, y por tanto, lo exótico tendría que venir de la mano de estos ingenieros-arquitectos, que en la arquitectura religiosa van a buscar la simplificación eliminando el ornamento, sin romper con la tradición, sino volviendo al barroco romano del segundo y tercer tercio del siglo XVII. De esta forma el foco compostelano pierde su influencia, trasladándose ahora a O Ferrol.

Pero si observamos el panorama artístico de la época en el resto de España, y concretamente en lo que se refiere a construcción de retablos o tabernáculos, observamos un fenómeno similar. Así, el de la capilla de San Julián y Transparente de la catedral de Cuenca, trazado por Ventura Rodríguez (1751-1752), obedece a un planteamiento neobarroco. Planta cóncava, frontón curvo partido con figuras de mármol blanco sobre él, medallón perforado en la parte superior entre volutas, predominio de la curva, materiales marmóreos de colores, bronces para las basas y capiteles de las columnas, rayos y otros adornos. Un planteamiento que será común y característico a todas las obras que se ejecutan en este momento, incluso antes de que asi se disponga por Real Orden.

Otro tanto se puede decir del retablo mayor de la catedral de Zamora, del mismo autor, también con planta cóncava, y del de la catedral de Segovia, diseñado por Francisco Sabatini (1768), en el que las curvas de las gradas, se contraponen a las de la planta, creando un juego de curvacontracurva, típicamente barroco.

Martín González ${ }^{5}$, nos habla de retablos neoclásicos hechos en Burgos según las normas dadas por la Real Academia, mencionando el proyecto de retablo para la capilla de la casa consistorial, de José Cortés del Valle. Constaba de dos cuerpos y ático. En el centro del principal se dispondria un lienzo de la Concepción, dentro de un marco a imitación del altar mayor de la iglesia de San Carlos de Roma ${ }^{6}$. Un testimonio más de lo que venimos apuntando.

${ }^{5}$ Martín Gonzalez, J. J., “Problemática del retablo bajo Carlos III", Fragmentos, núms 12-13-14, junio 1988.

${ }^{6}$ Ibidem, pág. 40 
UNA OBRA DE PEDRO IGNACIO DE LIZARDI, Y JOSÉ DE ELEXALDE

A finales del siglo xvII, la catedral de Lugo tenía ruinosas las dos naves del coro, y las siguientes hasta el trascoro, asi como el antecoro y capilla del altar mayor, lo que dio lugar a que en el año 1697 se trasladase el culto del Santísimo a la sacristia, que hiciera Domingo Antonio de Andrade.

Las obras a realizar fueron tasadas en 50.000 ducados, contribuyendo con 20.000, las siete ciudades del antiguo reino de Galicia. El rey concedió 2.000 doblones del Real Erario, y un arbitrio de 2 maravedis sobre el cuartillo de vino que se vendiese en la ciudad hasta completar la cantidad de 689.485 reales en que posteriormente fue tasada la obra por Lemaur.

El obispo puso 2.000 doblones, después dio, al igual que el Cabildo, 60.000 reales, haciendo el prelado una nueva aportación de 90.000 reales. El canónigo tesorero don Tomás Ramirez, dio 30.000 reales. El arzobispo de Santiago, don Bartolomé Rajoy y Losada, regaló 79.000, y el deán, Tomás de Anguiano, 20.000 destinados para arreglos de la capilla mayor.

Terminadas las obras de ésta, se iniciaron las de su acondicionamiento. En este sentido, el 23 de octubre de 1764, el Cabildo acordó que el arcediano de Neira, don José Antonio Cosentino de Tejada, elevase dos solicitudes: una a Carlos III, a través del marqués de Esquilache para que "permitiese al ingeniero don Carlos Lemaur, sin perjuicio de las ocupaciones en que está entendiendo del real servicio, que viniese de cuando en cuando, a reconocer el estado de la obra..., y diese sus direcciones a los maestros que hayan de correr con ella, y la otra para que los señores de la Real Cámara manden se entreguen los planos o mapas que formó aquel cuando vino al reconocimiento y tasa de dicha obra de orden de S. M., por desear el Cabildo se arregle a ellos"?

La autorización se recibió el día 10 de noviembre, y los planos elaborados por Lemaur el 15 de enero de 1765, traídos por el ordinario Crespo, consistentes en "cinco piezas, dos por lo correspondiente al perfil y plano de la capilla mayor, otras dos al perfil y plano de la fachada principal con sus dos torres, y otro del tabernáculo para la dicha capilla mayor, y todos con su justipie con su nombre y firmas del expresado Cabildo, ingeniero don Carlos Lemaur" ${ }^{8}$, acordándose que se entregasen al arcediano de Sarria para la ejecución de la obra.

Actas Capitulares del Cabildo. Lib. 17, fol. 366. Archivo de la Catedral de Lugo.

${ }^{8}$ Ibidem. 
Asi pues, tenemos que hubo un primer modelo de tabernáculo hecho por Lemaur, que se ha perdido y por tanto ignoramos como era, al que, en principio debería de ajustarse la obra. El 19 de enero se nombró una comisión formada por el deán, Tomás de Anguiano y Morillo; el tesorero, Tomás Rodriguez de Arellano; el magistral, Antonio Santomé Aguiar, y el secretario, Antonio Cosentino de Tejada, con el objeto de «ir pensando encargar y hacer diligencias para la fábrica del Tabernáculo de la capilla mayor en donde se ha de colocar el Señor Sacramentado, de modo que pueda estar dispuesto para luego que se concluya la obra de la bóveda de esta, y seguir menos tiempo con la incomodidad que hoy se experimenta con la precisa mudanza a la sacristia" ${ }^{9}$. Les encomiendan que se entiendan con el obispo, don Juan Sáenz de Buruaga (1762-1768), y con el arcediano de Sarria que estaba encargado de las obras. El deán renunció formar parte de la comisión debido a su edad y estado de salud, quedando formada sólo por tres individuos.

Como vamos a ver a continuación, el diseño del tabernáculo actual, fue realizado por Pedro Ignacio de Lizardi, aunque introducirá algunas modificaciones en su remate el encargado de ejecutarlo, José de Elexalde.

Fue entonces cuando el obispo decide encargar el tabernáculo a Pedro Ignacio de Lizardi, según consta en el acta capitular del 13 de junio, desplazándose a Lugo, "para tomar las medidas y disponer el tabernáculo, y su diseño, lo habia ejecutado éste, y empezado a trabajar en el planteado, el que deseaba perfeccionar luego que se retirase al puerto del Ferrol a donde estaba destinado por Su Majestad, y tenia precisión de pasar inmediatamente" ${ }^{10}$, acordando que se le gratificase.

El 18 de junio, el tesorero manifestó que la diputación capitular, de acuerdo con el obispo, habia entregado «al maestro llisardi, tres mil reales por razón del viaje que hizo desde el Ferrol a esta, dias de detención en ella para tomar las medidas, y disponer los mapas y planteado del tabernáculo que se ha de hacer en la capilla mayor" ", cuya cantidad habia entregado a cuenta de los 30.000 reales que ofrecia para ayuda de la obra. Pero es más, el 18 de noviembre de 1766, se entregaron al tesorero 27.000 reales, "que con tres mil que expresó haber entregado al maestro que hizo el modelo para el tabernáculo de la capilla mayor, conforman los treinta mil que tenia ofrecidos de limosna para su construc-

\footnotetext{
9 Ibidem.

${ }^{10}$ Ibidem, fol. 402.

"Ibidem, fol. 404.
} 


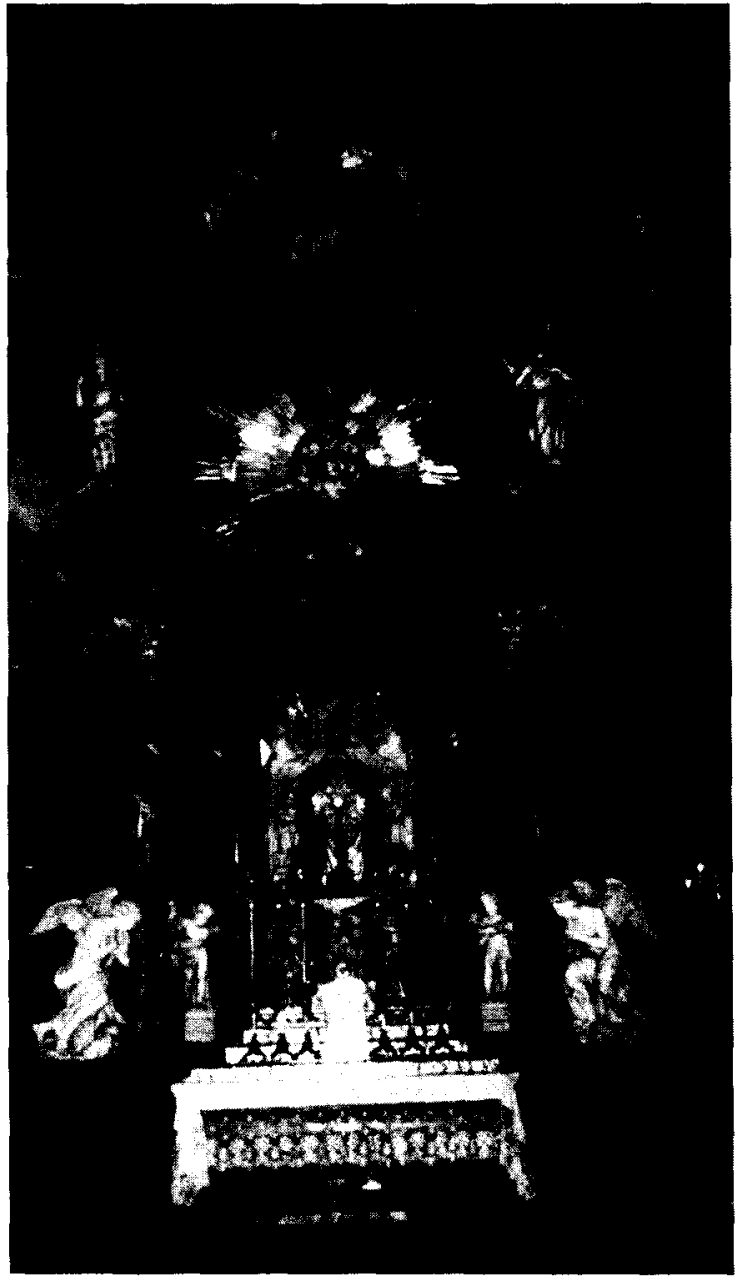

Fig. 1. Tabernáculo de la Catedral de Lugo obra de Pedro Ignacio de Lizaldi

ción" ${ }^{12}$. Por todo ello, no debe quedar duda de que el autor de la traza del actual tabernáculo es Pedro Ignacio de Lizardi.

El 25 de febrero de 1766, el tesorero comunicó que en cumplimiento de acuerdos anteriores para buscar quien hiciese el templete "se hallaba en esta ciudad don José Elixialde, profesor de arquitectura y dibujante

\footnotetext{
${ }^{12}$ Actas Capitulares del Cabildo. Lib. 18, fol.
} 
medidor en las reales obras del Ferrol, de quien presentaba un papel de propuestas... a la erección de la obra del tabernáculo de jaspes que se intenta hacer... con arreglo al modelo que está hecho para el efecto y que lo pondrá, y colocará en el sitio correspondiente a su coste y costa, con los bronceados y jaspes de la calidad que en el mismo papel expresa dentro del término de trece meses, que se han de contar desde primero de marzo de este presente año, en la cantidad, todo ello, de doscientos treinta y dos mil reales, y que se le han de entregar ahora, de pronto, setenta y cinco mil de ellos» ${ }^{13}$.

Se dio amplio poder al tesorero para que otorgase la escritura y le hiciese entrega de los 75.000 reales, donados el año anterior por el arzobispo de Santiago, don Bartolomé Rajoy y Losada. El obispo de Lugo, ofreció 20.000 reales, y la misma cantidad el deán Tomás de Anguiano, para ayuda de pintar y jaspear la capilla mayor o "para cualquiera de las obras que tiene el Cabildo dispuestas en ella" ${ }^{14}$. Por su parte el chantre ofreció 3.000 reales para el mismo fin.

Ese mismo dia se formaliza el contrato con Elexalde para la construcción del tabernáculo en el que se colocaria el Santisimo Sacramento, "y a este efecto se halla hecho un modelo o planta que subsiste en dicha Santa iglesia" ${ }^{15}$. Este modelo parece evidente que tenía que ser el confeccionado por Lizardi.

Se especifíca que todo lo que en él aparecía en jaspe negro, habria de ser de las canteras de Mañaria, en el señorío de Vizcaya, «de la misma especie de los que se colocaron en el real palacio de la villa y corte de Madrid" ${ }^{16}$.

Los cuatro machones o retropilastras situadas por la parte posterior o respaldo de las cuatro columnas, se revestirian con jaspe encarnado de las canteras de Loyola, y el fondo del tabernáculo con jaspe blanquecino matizado. El resto de los jaspes serían de la cantera de Loyola, excepto el frontal que en el medio llevaría jaspe verde de las canteras de Granada.

Tenía que colocar las cuatro esculturas, posiblemente los dos ángeles del remate, y los otros dos adoradores de la parte inferior, y dos jarrones en el sotabanco, hechas en piedra blanca de Salvatierra de Álava. Los

\footnotetext{
${ }^{13}$ Ibidem, fol. $13 \mathrm{v}$.

14 Ibidem.

${ }^{15} \mathrm{Leg}$. 534. Protocolos de José Antonio Mouriño. Año 1766. Archivo Histórico Provincial de Lugo.

16 Actas Capitulares del Cabildo. Lib. 18, fol. $13 \mathrm{v}$.
} 
capiteles y las basas de las cuatro columnas y de los cuatro pilares, serian de bronce dorado a fuego, con dos capas de oro.

El resto de los bronces estarían en el sol, con cinco serafines que salian entre las nubes, plateados, al fondo del sol dorado el Geová, un triángulo de mármol blanco bruñido, las cuatro palmas con sus cuatro colgantes de rosas que naciendo de las volutas superiores, rodeaban los arbotantes, terminando en las volutas inferiores, con su colgante de rosas al frente, y los dos colgantes del pabellón con sus dos laterales y uno al frente. La coronación del remate se haría con una imagen en madera de la Asunción.

El 8 de marzo, el tesorero presentó al Cabildo la escritura así como la fianza de don «Pedro Ignacio de Lizaldi arquitecto de S.M. en los arsenales de Ferrol... otorgada por dicho Lizaldi a primero de marzo de este presente año en los extramuros de la villa de Viveiro y feligresía de Santa Maria de Borracosa?" (Borralleiros) ${ }^{17}$. Esto constituye una prueba más de su vinculación con la obra, pues incluso se ocupó de algunos aspectos materiales, como el encargo de los bronces al platero ferrola no Juan Deogracias Durán y Sanjurjo, como veremos más adelante.

El arquitecto José de Elexalde permaneceria en Lugo por espacio de varios años dirigiendo las obras de la fachada principal de la catedral. Estaba soltero, y aunque en algunos documentos se dice que es natural del real sitio de San Ildefonso, en donde residian dos de sus hermanos, siendo probable que todos ellos trabajasen en el palacio real de La Granja, lo cierto es que su lugar de nacimiento y casa solariega estaba en Abadiano, merindad de Durango, en el señorío de Vizcaya. Eran nobles hijosdalgos. Sus padres fueron Mariano o Marcelino (Mrn) de Elexalde, y Maria de Pablos, y sus abuelos Simón de Elexalde y Maria de Beratúa ${ }^{18}$.

El 6 de septiembre, el tesorero da cuenta al Cabildo de que "el maestro encargado de hacer el tabernáculo avisaba estaria aquí presto con las piezas correspondientes a él, que era necesario se desocupase la casa y cárcel antigüa del Cabildo para poder poner en ella el taller para trabajarlas" ${ }^{19}$, y se acordó que la desalojase el platero, asi como que el arcediano de Sarria cuidase de la protección de las vidrieras de la capilla mayor «en atención a que podrá ser de gravisimo perjuicio el que estén abiertas al tiempo que se vayan colocando las piezas de dicho ta-

Ibidem, fol. 15.

${ }^{18}$ Leg. 98. Actas Capitulares de 1773. Consistorio 23-10, fols. 190-191. Véase A.H.P. de

${ }^{19}$ Actas Capitulares del Cabildo. Lib. 18, fol. 67 v. 

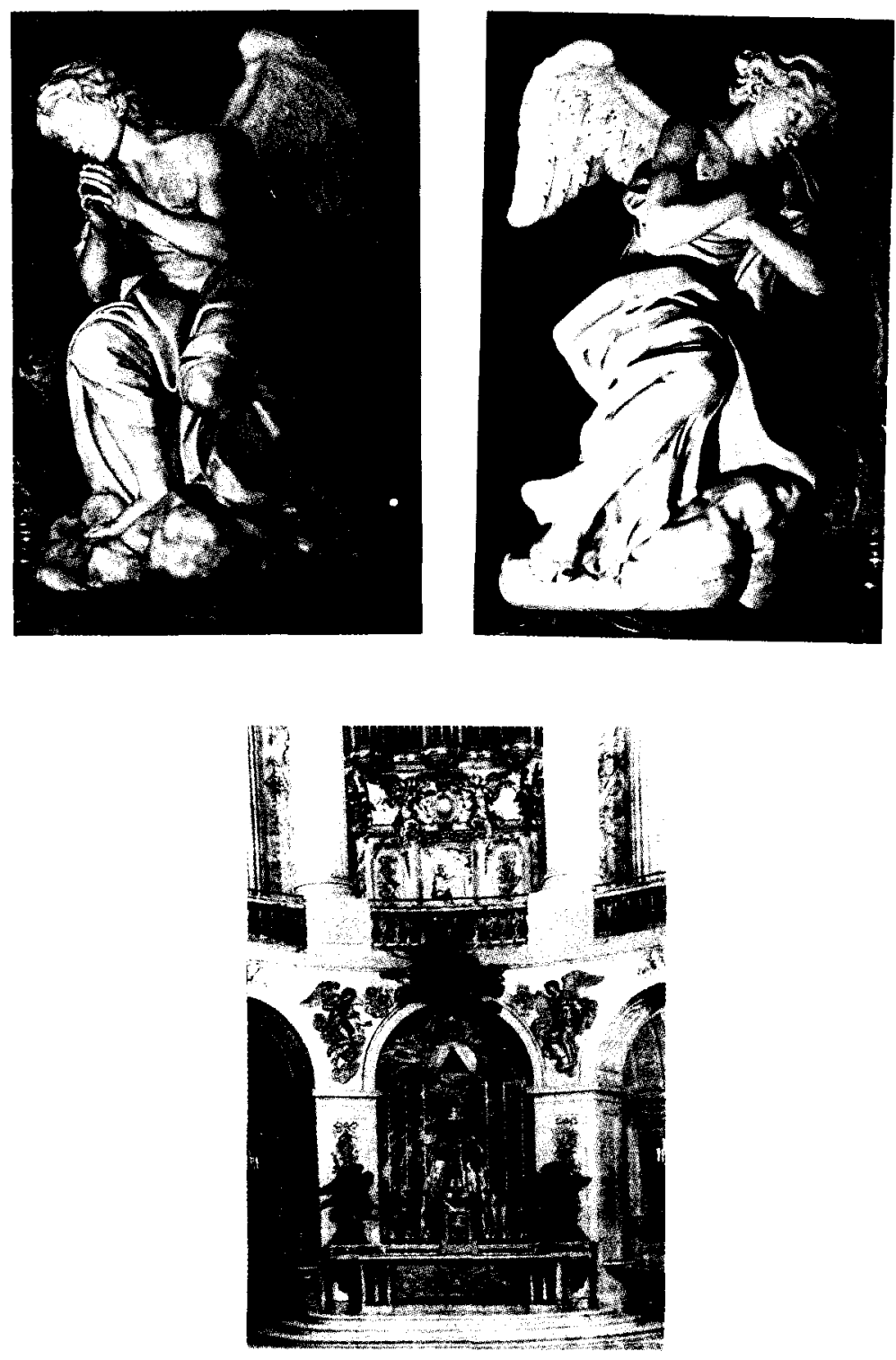

Figs. 2, 3 y 4 . Ángeles adoradores del tabernáculo lucense y altar de la Capilla Real de Versalles en donde aparecen con la misma actitud 
bernáculo, especialmente en tiempo de invierno a que nos vamos acercando ${ }^{20}$.

Estas vidrieras habian sido contratadas por el deán, el 14 de octubre de 1765, a José Opez, natural del reino de Bohemia y residente en A Coruña, que se compromete a utraer y conducir a esta ciudad para las rejas de dicha Santa Iglesia, setecientos vidrios cristalinos, de media vara de ancho y dos tercias de largo cada uno $(41 \times 55,5 \mathrm{~cm})$, y de grueso la mitad más de lo que tienen otros que están en poder de dicho señor deán» ${ }^{21}$. Tenia obligación de entregarlos sanos y enteros, pagando por cada uno 14 reales de vellón, de suerte que esperaba tenerlos en el mes de junio o julio de 1766, a no ser que surgiese alguna borrasca u otra contingencia en la navegación.

El 12 de junio de 1766, se había formalizado contrato con el platero ferrolano Juan Deogracias, para la ejecución de los bronces, pero parece ser que no cumplió con lo estipulado en el mismo, de suerte que el 7 de abril de 1768, se acordó que el contador del Cabildo pasase a la villa del Ferrol a "recaudar los maravedis que de los caudales dados para la construcción del tabernáculo y bronces, está adeudando el maestro del, Juan Gracia” ${ }^{22}$. Sobre esta misma cuestión, el 31 de mayo recibe el Cabildo un memorial del maestro Elexalde, en el que se dice que por el fiador don José Lizardi, se había entregado a Juan Gracia, platero del Ferrol, 30.000 reales del caudal de la obra del tabernáculo "para la construcción de basas y chapiteles de bronce; y por cuanto no ha cumplido con el trato expresado", suplicaba que se hiciesen las diligencias necesarias para recuperar dicha cantidad, "para así poder seguir hasta la conclusión de dicho tabernáculo" ${ }^{23}$. En vista de lo cual decidieron darle el dinero necesario para que pudiese continuar con el trabajo, y que el contador del Cabildo se trasladase a Ferrol a diligenciar la entrega del dinero.

Por un memorial que Elexalde presentó al Cabildo el 20 de diciembre, así como por la carta de pago otorgada el 4 de enero de 1769, conocemos las modificaciones que hizo en la obra. Dio al conjunto mayor altura, seis pies $(1,62 \mathrm{~m})$. La coronación la realizó «distinta y de mucho mayor coste», recibiendo por ello una propina de 18.000 reales «en atención a la nueva y primorosa idea de la coronación, mayor perfección, según arte del expresado tabernáculo, continuo desvelo conque ha procurado servir a di-

\footnotetext{
20 Ibidem.

${ }^{21}$ Leg. 534. Protocolos de José Antonio Mouriño. Año 1765. Archivo Histórico Provincial

22 Ibidem, fol. $159 \mathrm{v}$.

${ }^{23}$ Ibidem, fol. $165 \mathrm{v}$.
} de Lugo. 
chos señores Dean y Cabildo en otros varios encargos y plantas que ha puesto a su cuidado para otros distintos fines y obras durante su estancia en esta ciudad" ${ }^{24}$. Sabemos que hizo dos gradas para el presbiterio, y otra destinada al altar para colocar sobre ella las luces. Los jarrones que figuraban en el proyecto para el sotabanco, se sustituyeron por dos niños de piedra de Génova, colocados sobre repisas de jaspe.

Las plantas a las que hace referencia, eran las de la fachada principal, "con el plan de iglesia y sus medidas, según se pide de Madrid por el director don Ventura Rodríguez, el que si fuese del agrado de V.S.I. Ilevaré para explicarlo a boca» ${ }^{25}$.

El tabernáculo se organiza en un zócalo o sotabanco sobre el que se alza un único cuerpo y el remate. Este cuerpo principal, semicircular, se forma con las cuatro columnas y los retropilares correspondientes de sección cuadrada, con capiteles de orden corintio, sobre los que descansa el entablamento. En este, y sobre la prolongación del pilar, un angel de pie a cada lado, el de la derecha portando una lanza y el de la izquierda la cruz, mientras que de la prolongación de las columnas parten las volutas o arbotantes que sostienen la venera sobre la que descansa el conjunto escultórico de la Asunción de María, obra de Mateo de Prado. Dos ángeles recostados sobre los laterales de la venera, sostienen una cinta con la leyenda: SACRAMENTVM FIRMITER PROFITEMVR.

La parte central, destinada a expositor, es de mármol blanco, de composición muy movida. En la parte superior o dintel, tres serafines entre nubes de donde parten las cortinas, sostenidas por dos angelotes a ambos lados. En su parte inferior o peana, dos ángeles a los lados y otros dos serafines entre nubes. Nos resulta inevitable la evocación del Transparente de la Catedral de Toledo (1721-1732), obra rococó de Narciso Tomé. El conjunto se remata con rayos de bronce, como corresponde a la Divinidad, a la luz, el Cristo helios o Sol Invicto.

En la parte central del entablamento, situado entre el cuerpo principal del baldaquino y su remate, se destina a la representación de la Divinidad en su simbiosis con el sol formado por tres grupos concéntricos de haces radiantes, que albergan en el centro las cabezas de tres serafines entre nubes, en mármol blanco, en cuyo centro se encuentra la representación simbólica de Geová: el triángulo con el ojo.

En el sotabanco, a ambos lados de la mesa del altar y sobre dados, dos ángeles adoradores de mármol blanco, y entre las columnas, dos an-

${ }^{24}$ Leg. 535. Protocolos de José Antonio Mouriño. Año 1769, fol. 1-2 v.

${ }^{25}$ Actas Capitulares del Cabildo. Lib. 18, fol. 217. 


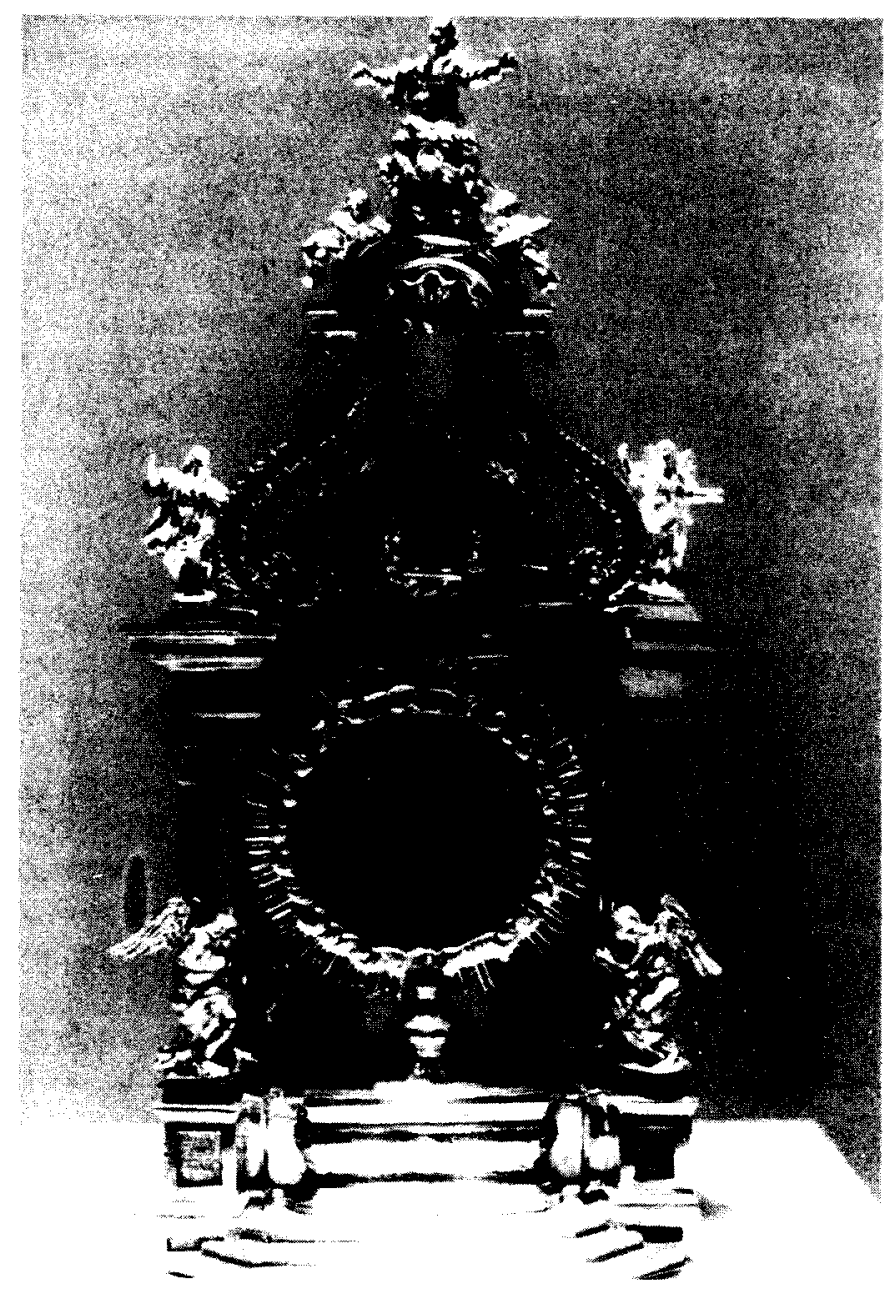

Fig. 5. Ostensorio regalado por el Cabildo lucense al arzobispo Rajoy, reproduciendo el tabernáculo o altar mayor de la catedral. Parroquia de Pontedeume (La Coruña)

gelotes del mismo material, portando, el de la derecha un haz de espigas, y el de la izquierda sostiene un sarmiento con racimos de uvas, en clara alusión al culto eucaristico.

\section{EL BARROCO ROMANO COMO MODELO COMPOSITIVO}

La confusión habida en torno a la autoria del tabernáculo, adjudicándosela a Carlos Lemaur, llevó a que se buscasen en Francia sus posibles 

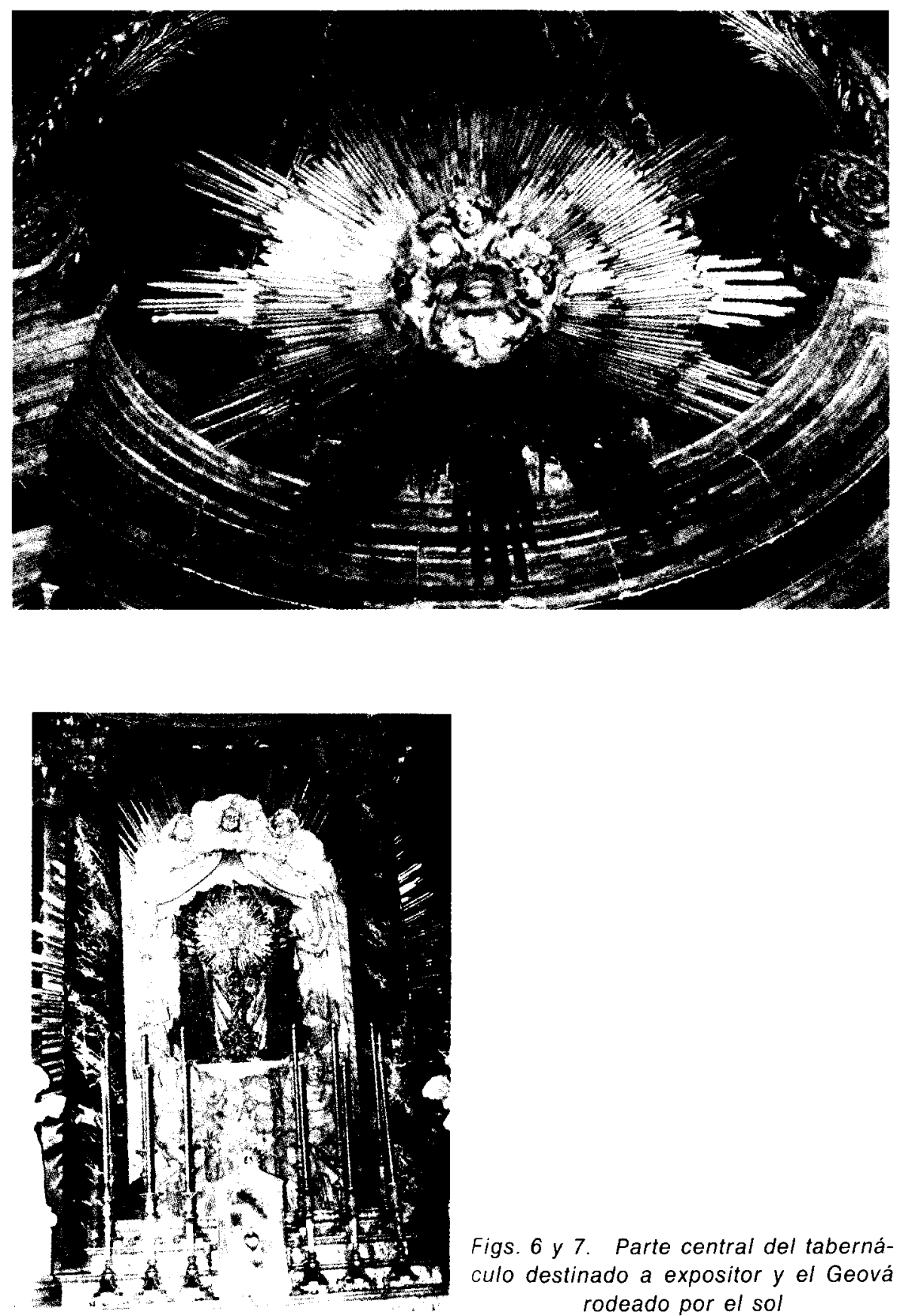

Figs. 6 y 7. Parte central del tabernáculo destinado a expositor y el Geová rodeado por el sol 


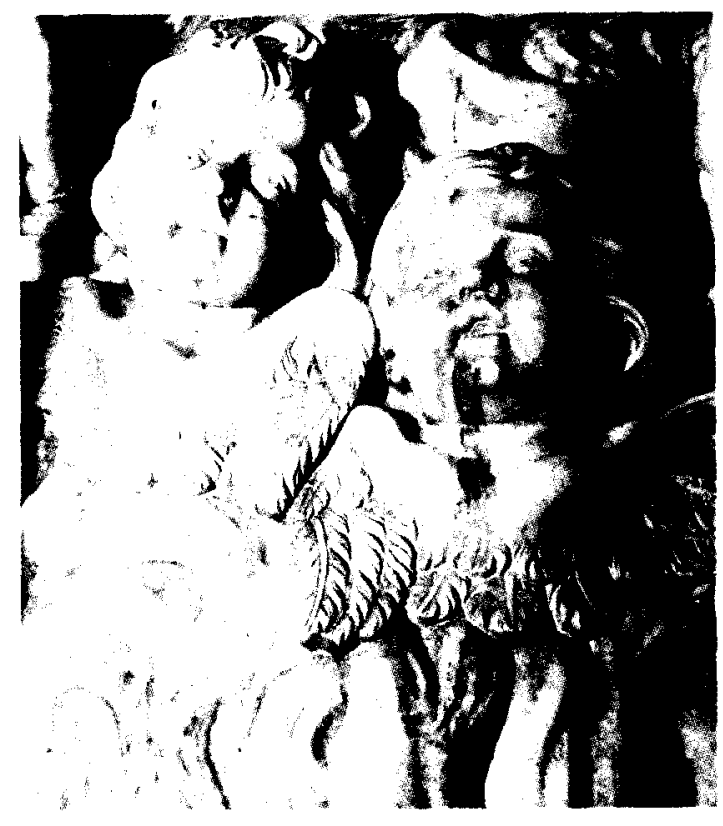

Figs. 8,9 y 10 . Serafines entre nubes y angelotes con los simbolos eucaristicos
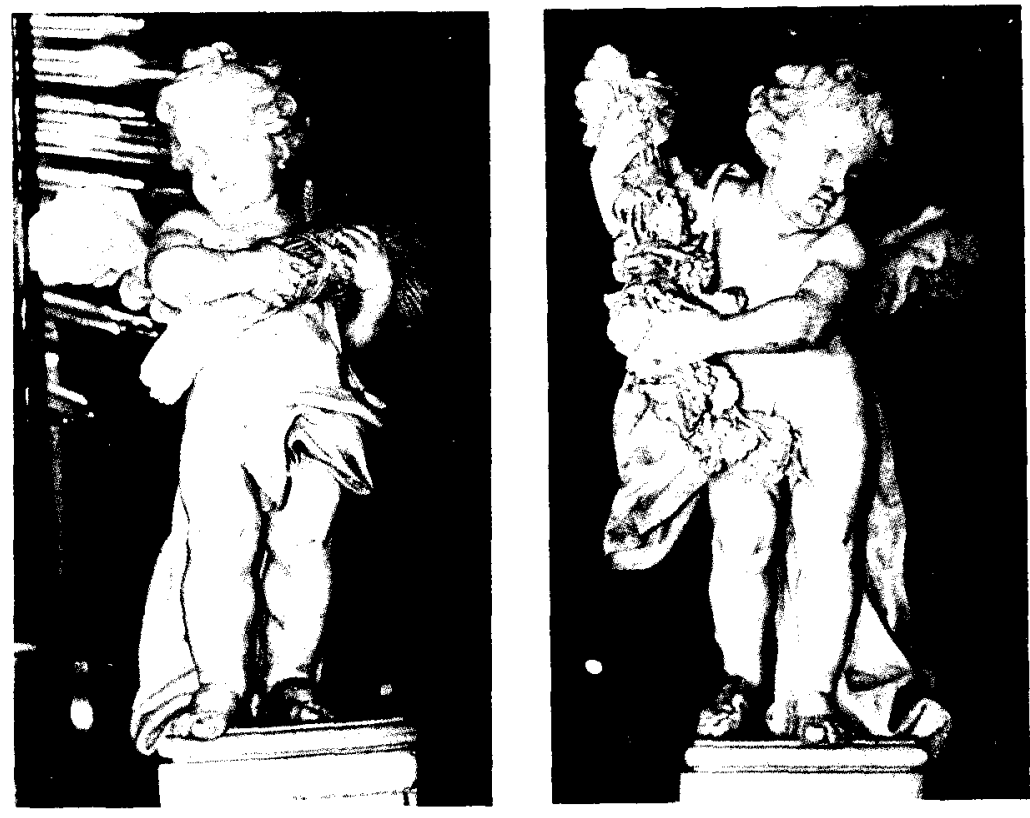
modelos, y en efecto se encontraron algunos paralelos, como el caso del tabernáculo de Saint Leu, diseñado por Juste-Aurèle Meissonnier.

Asi, Rosende consideró acertada adjudicar la autoría a Lemaur, sugiriendo una observación en el ambiente retablístico francés, en el cual se podria haber inspirado, apuntando que el "baldaquino del Val-de-Grace, construido sobre planos de Bernini, se convirtió en prototipo de una amplia serie a cuyo éxito contribuyó también el grabado» ${ }^{26}$.

Cita también la influencia que tuvieron los diseños de Gilles-Marie Oppenord, en especial el baldaquino para Saint-Germain-des-Près, en París, que sirvieron de modelo para los realizados por el hermano Guillaume de La Trembloye, dando lugar a prototipos ampliamente divulgados, levantados sobre planta cuadrada, circular o semicircular, con una estructura de columnas, rematada por volutas, citando el de la cartuja de Auray y el de la iglesia del Salvador de Rennes. En la linea marcada por estos dos arquitectos franceses, es en la que piensa que gravita «la traza de Lemaur para el retablo lucense" ${ }^{27}$.

Debido al error en la autoria, creo que es necesario reconducir este debate $y$, sin desautorizar la via francesa como prototipo, debemos recurrir directamente a la romana, especialmente a Bernini, en cuyo baldaquino de la basilica de San Pedro se inspiraron todos.

En el caso de Lugo, la fuente de inspiración es, a nuestro entender, Bernini al igual que otros arquitectos, incluso italianos, como el padre Andrés Pozzo. Frente al sistema poligonal de acoplamiento de los distintos planos que conformaban los retablos renacentistas, como el que habia que sustituir de Cornelius de Holanda, la adaptación a la forma cóncava de un ábside, o como en el caso de nuestra capilla mayor, de un deambulatorio, es una solución del barroco romano. La adaptación del retablo a la curva, la vamos a encontrar en el proyecto que hizo Bernini para la capilla de los Raimondi en San Pietro in Montorio (1636). En él podemos apreciar la similitud existente en cuanto a la organización del cuerpo principal, que consta de un entablamento curvo sostenido por columnas pareadas de orden corintio, reservándose la calle central para albergar el motivo iconográfico. Esto viene a ser, en esencia, el cuerpo del tabernáculo que estamos estudiando.

En la capilla de los Cornaro, de Santa Maria de la Victoria, aunque el recinto es rectangular, el retablo responde a la misma estructura, pero en este caso el entablamento es convexo con el objeto de hacer pasar la

\footnotetext{
${ }^{26}$ Rosende Valdés, Andrés A.

2i Ibidem.
} 


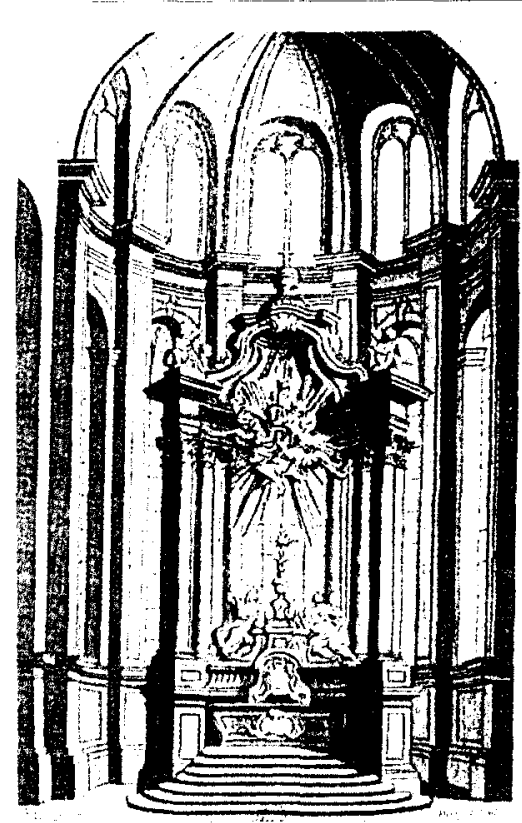

Fig. 11. Proyecto de tabernáculo para la iglesia de Saint Leu de Paris, realizado por Meissonnier

Fig. 12. Proyecto de tabernáculo o altar para la Inmaculada, del padre Andrea Pozzo

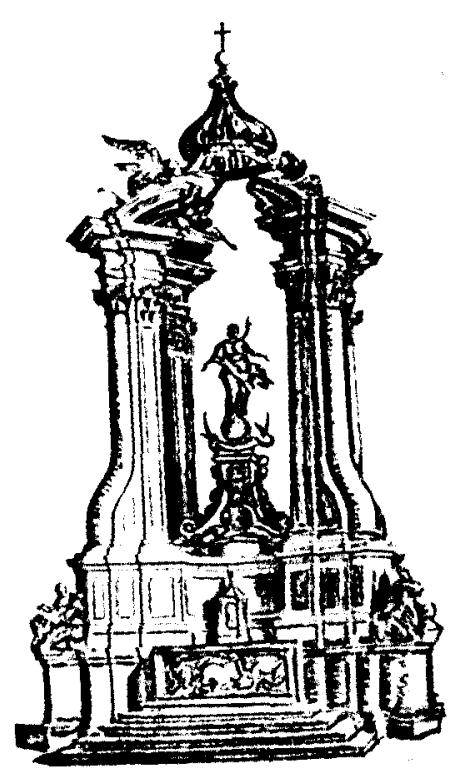




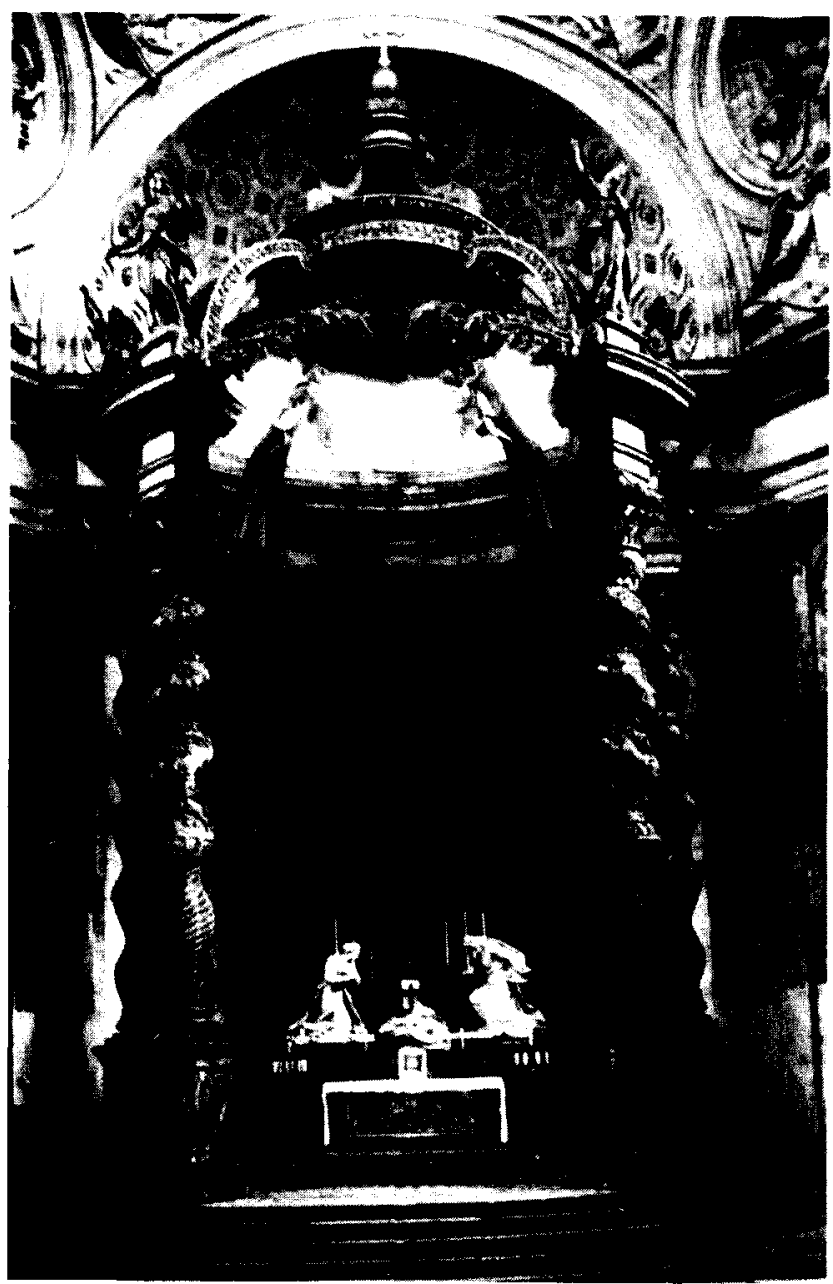

Fig. 13. Baldaquino de Val-de Grace, construido sobre planos de Bernini

luz cenital por su parte posterior, para que incida sobre el grupo escultórico.

Pero es más. El tabernáculo lucense se remata con volutas o arbotantes que sostienen el grupo de la Asunción de Maria, con esculturas de pie sobre el entablamento en la prolongación de los retropilares y las columnas, respectivamente, y en la parte central se pone el sol. En el baldaquino de San Pedro, nos encontramos con algo similar, sólo que en este caso las volutas o arbotantes sostienen la bola del mundo y la cruz, y en la parte central se coloca un grupo de ángeles sosteniendo la tiara 


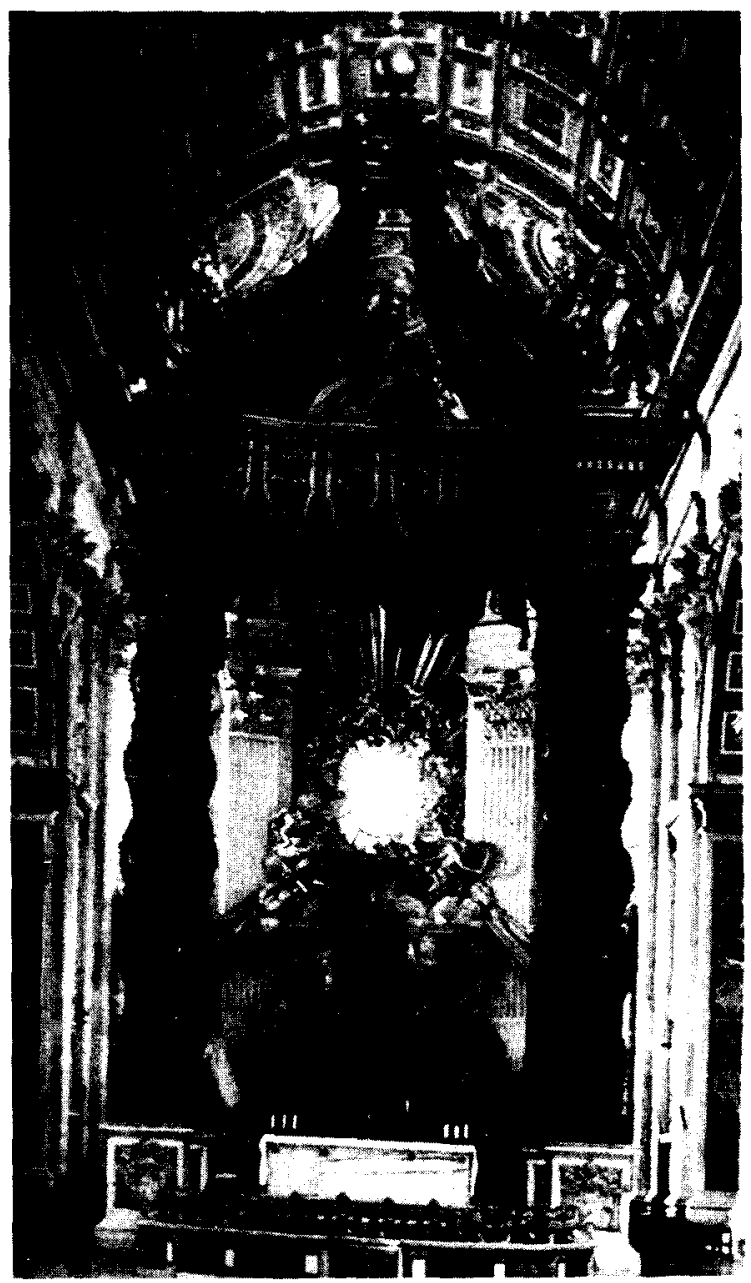

Fig. 14. Baldaquino de Juan Lorenzo Bernini, en la basilica de San Pedro de Roma (1624)

papal, porque el astro rey, con el Espiritu Santo, se presenta enmarcado por el baldaquino formando parte del conjunto de la Cátedra de San Pedro (1656-1665).

Consecuentemente, consideramos que el prototipo del cuerpo principal del tabernáculo de Lizardi, tiene su paralelismo con el retablo de la capilla de los Raimondi, para el cuerpo central, y en cuanto al remate, en el baldaquino de San Pedro y su Cátedra. Pero esta influencia italiana se hace más patente en el proyecto de altar para la Inmaculada, que a finales del siglo xvII, diseña el padre Andrea Pozzo, en donde la concavi- 
dad del mismo, la organización en un sólo cuerpo con remate, la presencia alternada de columna con fuste liso y capitel corintio, con retropilar de fuste cuadrado y capitel de orden clásico, asi como figuras sobre pedestales a ambos lados, nos está evocando la obra lucense.

Por otra parte, conviene destacar que su remate sostenido por ángeles, se compone de una serie de volutas que forman una corona, terminada con una cruz sobre bola, que viene a ser una reinterpretación del remate del baldaquino de Bernini, la misma solución que podemos ver en el de Meissonnier. Habria que preguntarse hasta que punto esta obra francesa está inspirada en la del padre Pozzo. De lo que no cabe la menor duda, es de que todas ellas parten de modelos y elementos berninescos, de los que tampoco se escapó el censor de la real Academia, Ventura Rodriguez, cuando diseñó el remate del altar de la iglesia parroquial de Renteria.

Pero incluso el conjunto de la capilla mayor tiene un planteamiento barroco. Las pinturas de la bóveda, conforman una escenografia adecuada para que el espectador tenga la sensación de que flota la Asunción del remate del tabernáculo, recurso destinado a esa teatralidad y conquista del espacio a la que fue tan aficionada la iconografia barroca en los éxtasis y tranfiguraciones, levitaciones, glorias, inmaculadas, asunciones, etc.

En cuanto a otros elementos, como los ángeles adoradores, son utilizados por Bernini en el entablamento del altar mayor de San Agustín de Roma (1628), y los veremos también en el altar de la capilla del palacio real de Versalles. Incluso el hecho de que los materiales empleados sean polícromos, combinando los jaspes o mármoles con los bronces, y las esculturas principales en mármol blanco, contribuye a acentuar las semejanzas con estas obras romanas.

En este sentido hay que destacar que el tabernáculo de Lugo, es una de las obras que se hace en materiales estables y permanentes, recomendados diez años después por el conde de Floridablanca, en nombre del rey, en la circular a los arzobispos, obispos, cabildos y prelados, sobre obras en las iglesias, enviada el 25 de noviembre de 1777, que establece el control oficial de las mismas por parte de la Real Academia de San Fernando.

Por un lado se pretendia la intervención de los que se formaban en ella, y por otro, evitar malgastar los dineros públicos o privados en obras perecederas y de dudosa calidad artistica. La Academia habia llamado la atención de Carlos III, sobre «las tristes y dolorosas experiencias que se repiten frecuentemente en los sagrados templos, en que por lo frágil y combustible de las materias de que se componen los retablos, adornos y 
techumbres de los más de ellos, y por no adaptar exactamente su forma a las reglas del arte y del buen gusto, unos perecen lastimosamente entre las llamas... y otros desdicen de la majestad de aquellos lugares en que damos culto al omnipotente, y veneramos los más sublimes objetos de la religión» ${ }^{28}$.

Por decoro, buena inversión, reputación de los promotores de las obras, permanencia y seguridad de las mismas, se establecia la consulta previa a la Academia de San Fernando, recomendando que en lo posible se evitase «emplear maderas, especialmente en los retablos y adornos de los altares, puesto que apenas hay ciudad en el Reino en cuyas cercanias no abunden mármoles, $u$ otras piedras adecuadas, mediante 10 cual, no sólo se evitara gran parte del riesgo de los incendios (mayormente si se redujere el número de luces a lo que pide el decoro del templo y dicta la devoción seria y majestuosa practicada en las catedrales en las catedrales y en las capillas de S.M.), sino también se reformará el enorme infructuoso gasto de los dorados, expuestos a ennegrecerse y afearse en breve tiempo, y se promoverá el adelantamiento y digno ejercicio de las artes con monumentos de materias permanentes, pudiendo, en caso necesario, suplir muy bien los estucos, que son menos costosos que los mármoles y jaspes" ${ }^{29}$.

Por último, quisieramos hacer referencia al retablo mayor de la catedral de Tui estudiado por Rosende, en el que, acertadamente, quiere "ver sugerencias que apuntan en dirección a una obra de mayor empeño, como el retablo mayor de la catedral de Lugo" ${ }^{30}$. Hay base para pensarlo así, dado que el Cabildo de Tui solicitó información al de Lugo, el cual, en 4 de septiembre de 1784, acordó enviar un «diseño del tabernáculo de esta Santa Iglesia, y su coste, con enmienda de algún defecto si se advirtió después" ${ }^{31}$. El coste del Tabernáculo habia sido de 261.901 reales.

La fecha que da Rosende de contestación del Cabildo de Lugo, 11 de diciembre de 1814, tiene que estar equivocada, probablemente por un error de transcripción. Parece más lógico que el año sea el de 1784, asi se podrán comprender las observaciones que hace el Cabildo lucense sobre las dificultades conque se iban a encontrar para obtener la licencia del Gobierno por los desorbitados gastos que supondria hacer una obra como la de Lugo, teniendo en cuenta que "ese altar mayor es decente y

${ }^{28} \mathrm{Leg}$. 32-7/2. Circular a los arzobispos, obispos, cabildos y prelados sobre obras en las iglesias. Año 1777. A. R. A. S. F. Madrid.

29 Ibidem.

30 Rosende Valdés. A., Op. cit, pág. 79.

31 Actas Capitulares del Cabildo. Lib. 22, fol. 12 v. A. C. de L. 
todavia nuevo» ${ }^{32}$, en alusión, posiblemente, al que se había levantado a finales del siglo xvII.

\section{EL ARZOBISPO RAJOY Y EL TABERNÁCULO}

Uno de los mecenas de las obras de la catedral de Lugo, y muy especialmente de su tabernáculo, fue su antiguo doctoral, el arzobispo de Santiago, don Bartolomé Rajoy y Taboada. El 9 de enero de 1765, el Cabildo recibe una carta fechada en Lestrove, en la que comunicaba otro donativo «de mil doblones de oro con el fin de que se empleasen en el mayor adorno del altar de la capilla mayor" ${ }^{33}$.

La inauguración de las obras tenia que ser todo un acontecimiento, por lo que decidieron que ésta fuese el dia del Corpus Christi y que se invitase al arzobispo. El día 20 de abril el Cabildo escribe al Ayuntamiento para comunicarle que estaba concluida «la obra de la capilla mayor y nuevo tabernáculo que se dispuso fabricar para más decente trono de nuestro Dios Sacramentado, y teniendo noticia de que el ilustrísimo señor arzobispo de Santiago, nuestro bienhechor, pensaba en dar una nueva prueba, pero la mayor y más relevante, en confirmación de la suma veneración y entrañable amor que mantuvo siempre a aquella divina reliquia y a la sagrada imagen de su Santísima Madre, nuestra patrona y señora de los Ojos Grandes, concurriendo a adorarlos personalmente» ${ }^{34}$.

El Ayuntamiento quiso manifestar también su gozo por el acontecimiento, para lo que acordó que en la noche en que se decidiese por el Cabildo, "se disparen fuegos, se iluminen estas Casas Consistoriales, y al tiempo de la procesión, se echen algunas diferencias de fuegos desde ellas, y se prevenga a los cuatro gremios de esta ciudad el que hagan sus danzas y más correspondientes festejos de manera que se conozca el gozo conque todos manifiestan el que debe dar tan alto y superior motivo" ${ }^{35}$.

También acordaron tributar al arzobispo «los mayores obsequios como a bienhechor de esta Santa Iglesia, y un patricio que tanto se interesa en honor y gloria de la nación» ${ }^{36}$. Para ello varios caballeros capitulares sal-

${ }^{32}$ Op. cit., pág. 84.

${ }^{33}$ Actas Capitulares del Cabildo. Lib. 17, fol. 366 A. C. de L.

${ }^{34}$ Leg. 94. Actas Capitulares de 1769. Anexo consistorio 22-04. fols. 185-186. A.H.P. de L.A.

33 Ibidem. Consistorio 16-05, fol. 205.

36 Ibidem. 
drian a recibirlo a las afueras de la ciudad, acudiendo después a visitarlo el resto de los miembros del Ayuntamiento.

En la noche del día 23 de mayo, acudió a devolver la visita al Ayuntamiento, desde cuyas casas consistoriales presenció «la función de fuego que se hizo en la plaza, como también el ilustrísimo señor obispo de esta ciudad, manifestando lo continuará en las más en que la hubiese” ${ }^{37}$.

La ceremonia inaugural tuvo lugar el dia 25 de mayo. El día 28, domingo de la infraoctava, se celebraba la ofrenda del Reino de Galicia y el Ayuntamiento, por medio de don José Baamonde y don José Benito de Páramo, pidió al arzobispo que presidiese la función, lo que asi hizo «y recibió de mano del diputado la oferta, respondiendo a ella con las más vivas expresiones de la constante fe y religión de este reino, rogando al Todo Poderoso por sus felicidades y cediendo todo en el mayor honor del reino que le dispensa este ilustrísimo príncipe tan interesado en la mayor gloria de la nación» ${ }^{38}$.

Por su parte el Cabildo quiso mostrarle su agradecimiento, y el 13 de mayo se propone hacerle un obsequio, habiéndose concebido "la obra de un tabernáculo de plata sobredorada, imitante al fabricado de jaspe en la capilla mayor, y unas medallas de oro de Nuestra Señora de los Ojos Grandes para su ilustrísima, y su familia» ${ }^{39}$, cuyo coste fue de once mil reales de vellón. Esta pieza se encuentra en la actualidad en la iglesia parroquial de Pontedeume, villa natal del arzobispo, a la que quiso distinguir con este regalo.

Otra pieza similar fue hecha y donada al arzobispo de Zaragoza, don Juan Sáenz de Buruaga, que había sido obispo de Lugo, «en reconocimiento a las dádivas con que contribuyó para la construcción del principal de la capilla mayor y las que piensa continuar su piedad para su adorno» ${ }^{40}$. Esta pieza costó 5.855 reales de vellón, acordándose su envio a Zaragoza el dia 9 de diciembre. La actual custodia, fue obsequio de este prelado.

${ }^{37}$ Ibidem. Consistorio 24-05.

${ }^{38}$ Ibidem. Consistorio 28-05, fol. 217.

${ }^{39}$ Actas Capitulares del Cabildo. Lib. 18, fol. 245 v.

${ }^{40}$ Ibidem. 